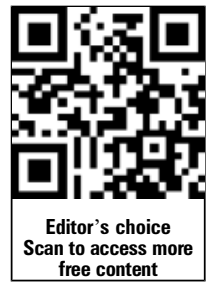

${ }^{1}$ Department of Sports Medicine, Oslo Sports Trauma Research Center, Norwegian School of Sport Sciences, Oslo, Norway

${ }^{2}$ The Football Association of Norway, Oslo, Norway ${ }^{3}$ Department of Medicine, Diakonhjemmet Hospital, Oslo, Norway

${ }^{4}$ Department of Cardiology, Akershus University Hospital, Lørenskog, Norway

Correspondence to Dr Hilde Moseby Berge, Department of Sports

Medicine, Oslo Sports Trauma Research Center, Norwegian School of Sport Sciences, PO Box 4014 Ullevaal Stadion, Oslo 0806, Norway: hilde.moseby.berge@nih.no

Accepted 25 February 2013 Published Online First 16 March 2013

\title{
High ambulatory blood pressure in male professional football players
}

\author{
Hilde Moseby Berge, ${ }^{1}$ Thor Einar Andersen, ${ }^{1,2}$ Erik E Solberg, ${ }^{3}$ Kjetil Steine $^{4}$
}

\section{ABSTRACT}

Background No data exist on ambulatory blood pressure (ABP) in athletes.

Objectives To identify ABP and examine recommended follow-up of high office blood pressure (OBP) in male professional football players and secondary study indicators of sympathetic activity.

Methods Players with high OBP (cases) from a previous screening of 594 players $(n=28)$ were matched for age and ethnicity with players with optimal OBP (controls). High ABP was defined as a mean of $\geq 135 / 85 \mathrm{~mm} \mathrm{Hg}$ during daytime and $\geq 120 / 75 \mathrm{~mm} \mathrm{Hg}$ during night-time. The players replied to questions regarding follow-up of high OBP. High night-time ABP and lack of nocturnal dip ( $\leq 10 \%$ decline in average BP) were taken as indicators of increased sympathetic activity.

Results 26 cases and 26 controls, mean age $28 \pm 4$ years, were included. $15(58 \%)$ of the cases had sustained hypertension and $11(42 \%)$ white coat hypertension. Among the controls, 17 (65\%) had normotension and $9(35 \%)$ masked hypertension. ABP during night-time was high in $23(88 \%)$ of the cases and in $16(64 \%)$ of the controls, and nocturnal dip was absent in $9(35 \%)$ and $11(42 \%)$, respectively. $10(38 \%)$ of the cases had no follow-up of high OBP. Conclusions More than one-third of the players with optimal OBP had masked hypertension during daytime and more than half of all players had high ABP during night-time, which are novel findings in athletes. Together with the reduced nocturnal dip, this might indicate increased sympathetic activity. Follow-up of high OBP after preparticipation screening is random and should be organised.

\section{INTRODUCTION}

Blood pressure (BP) status in athletes is mainly derived from preparticipation office BP (OBP) screening on one occasion without organised follow-up. ${ }^{1}$ The common opinion is that $\mathrm{OBP}$ is higher than ambulatory blood pressure (ABP). ${ }^{2} \mathrm{ABP}$, which can reveal masked hypertension, is recommended as an adjunct to OBP measurements by international guidelines, ${ }^{3}$ and is superior to OBP in predicting cardiovascular (CV) events. ${ }^{4}$ There are, however, no studies of masked hypertension in athletes, despite the fact that young age, male gender, physical activity and mental stress characterise both athletes and people with masked hypertension. ${ }^{5-7}$

During preparticipation cardiac screening of male professional football players in Norway, 7\% had high OBP $(\geq 140 / 90 \mathrm{~mm} \mathrm{Hg})$, and there was a significant linear relationship between increasing OBP and indexed LV mass BSA. ${ }^{8}$ Increased BP was also significantly associated with increased heart rate (HR) and pulse pressure (PP) ${ }^{8}$ both of which might be reckoned as indicators of sympathetic activity. ${ }^{10}$ Players with high BP were recommended additional BP recordings after the screening, but there was no organised control.

The main aims of this investigation were to identify the prevalence of high ABP in male professional football players in Norway and to examine the players' compliance to recommended follow-up of high BP. Second, we wanted to study if indicators of sympathetic activity were increased in players with high BP.

\section{METHODS}

From February to April 2008, male professional football players from the Norwegian elite and first division leagues underwent mandatory preparticipation cardiac screening ${ }^{11}$ when attending a preseason training camp in La Manga, Spain. ${ }^{8}$ They responded to a questionnaire regarding their height and weight, from which body mass index (BMI) was calculated. They were also asked if their ethnicity was Caucasian (white), Afro-American (black) or other. When in doubt, birthplace or parents' homeland was used. If the parents came from different continents, the players were categorised as 'mixed' ethnicity.

Based on the players' BP from the screening in 2008, we designed a case-control study and recorded ABP from October 2010 until February 2011. All available players with untreated high BP $(\mathrm{n}=37)$ were assessed for eligibility as cases, excluding players living abroad. Controls were randomly selected from players with optimal BP $(n=250)$, according to a predefined protocol, and individually matched for age group (or maximum age difference 4 years), ethnicity and professional football team. All participants gave informed written consent. The study was approved by the Regional Ethical Committee.

\section{Office blood pressure}

$\mathrm{BP}$ was measured at least $1 \mathrm{~h}$ after exercise and after 5 min rest in a sitting position, using a validated automatic BP monitor (Dinamap ProCare DPC300N, GE, Milwaukee, Wisconsin, USA). Systolic BP (SBP) and diastolic BP (DBP) were registered as the mean of two consecutive BP recordings.

\section{Ambulatory blood pressure}

On the recording day, the players resigned from snuffing and exercise in the morning, and they did not participate in football or other sport activities for the following $24 \mathrm{~h}$. Outside this, they engaged in normal activity in accordance with the guidelines from the European Society of Cardiology and the 
European Society of Hypertension. ${ }^{3}$ The project leader (HMB) fastened the cuff, adjusted it to the upper-arm girth of the players' non-dominant arm and the ABP device (Tonoport, Cardiosoft, GE Healthcare, Oslo, Norway) was kept in a belt. The ABP device was programmed with software CardioSoft V.6.61 to obtain BP readings at 30 min intervals from 7:00 until $21: 59 \mathrm{~h}$ and at $60 \mathrm{~min}$ intervals during the night. Night-time was later adjusted to reported time in bed, and daytime the rest of the time. During daytime, they were informed to relax their arm when the recordings started. Measurements were automatically repeated when registered as not valid. The players also reported if they used any medications, if something extraordinary occurred during the recording period, and if they had undergone additional $\mathrm{OBP}$ or $\mathrm{ABP}$ recordings after the screening in 2008 .

\section{Data definitions}

Among the 52 players, daytime ABP monitoring was successfully committed in all players, at night-time in 51 players. The mean valid measurements were $26.9 \pm 4.5$ and $8.3 \pm 3.4$ during the day and night, respectively. According to the published guidelines, high OBP was defined as $\geq 140 / 90 \mathrm{~mm} \mathrm{Hg}$, high ABP during daytime $\geq 135 / 85 \mathrm{~mm} \mathrm{Hg}$, during $24 \mathrm{~h} \geq 130 / 80 \mathrm{~mm} \mathrm{Hg}$ and during night-time $\geq 120 / 75 \mathrm{~mm} \mathrm{Hg} .{ }^{3}{ }^{12}$ We used daytime ABP, which is most common, when the players were categorised in four BP subgroups: ${ }^{13}$ True normotension (OBP $<140 / 90 \mathrm{~mm} \mathrm{Hg}$ and daytime $\mathrm{ABP}<135 / 85 \mathrm{~mm} \mathrm{Hg}$ ), white-coat hypertension (OBP $\geq 140 / 90 \mathrm{~mm} \mathrm{Hg}$ and daytime $\mathrm{ABP}<135 / 85 \mathrm{~mm} \mathrm{Hg}$ ), masked hypertension (OBP $<140 / 90 \mathrm{~mm} \mathrm{Hg}$ and daytime ABP $\geq 135$ / $85 \mathrm{~mm} \mathrm{Hg}$ ) and sustained hypertension (OBP $\geq 140 / 90 \mathrm{~mm} \mathrm{Hg}$ and daytime $\mathrm{ABP} \geq 135 / 85 \mathrm{~mm} \mathrm{Hg}$ ). After ABP monitoring, both players with true normotension and white-coat hypertension were defined as normotensive players, and both players with masked hypertension and sustained hypertension were defined as hypertensive players.

PP was calculated as the difference between systolic BP (SBP) and diastolic BP (DBP). Mean arterial pressure (MAP) was defined as DBP $+1 / 3$ (SBP-DBP). Nocturnal dip in BP was defined as a mean $10 \%$ decline in average SBP or DBP at night compared with daytime. ${ }^{14}$ High $\mathrm{HR},{ }^{10}$ increased PP and ${ }^{9}$ nighttime ABP, and lack of nocturnal dip ${ }^{14}$ were considered as indicators of increased sympathetic activity.

\section{Data analysis}

The outcome variables for this study were mean SBP, DBP, MAP, HR, PP and nocturnal dip in SBP and DBP. Correlation between office and daytime ambulatory MAP was tested using Pearson's bivariate correlation analysis. Differences between two groups were analysed using $t$ tests for continuous variables, and Fisher's exact tests for categorical variables. Differences in means between all BP subgroups were calculated using analysis of variance test for trend for continuous variables, and linear-by-linear analysis for categorical variables (table 1). Differences in means between the subgroups were calculated using the Bonferroni

Table 1 Comparisons of all 52 players divided into four blood pressure subgroups defined by office and ambulatory blood pressure

\begin{tabular}{|c|c|c|c|c|c|}
\hline \multirow[b]{2}{*}{ Variables } & \multicolumn{2}{|c|}{ Normotension ABP $(n=28)$} & \multicolumn{2}{|l|}{ Hypertension ABP ( $n=24)$} & \multirow[b]{2}{*}{ p Value } \\
\hline & $\begin{array}{l}\text { True normotension } \\
(n=17)\end{array}$ & $\begin{array}{l}\text { White coat hypertension } \\
(n=11)\end{array}$ & $\begin{array}{l}\text { Masked hypertension } \\
(n=9)\end{array}$ & $\begin{array}{l}\text { Sustained hypertension } \\
(n=15)\end{array}$ & \\
\hline Age (years) & $27.7(4.2)$ & $29.5(3.6)$ & $28.7(4.6)$ & $27.7(4.0)$ & 0.95 \\
\hline $\begin{array}{l}\text { Heart rate, daytime (beats/ } \\
\text { min) }\end{array}$ & $63.7(9.8)$ & $60.3(6.6)$ & $65.4(3.4)$ & $62.6(8.0)$ & 0.98 \\
\hline \multicolumn{6}{|l|}{ Office blood pressure $(\mathrm{mm} \mathrm{Hg})$} \\
\hline Systolic & $114.4(3.6)$ & $142.2(8.7)$ & $113.9(4.2)$ & $145.4(6.4)$ & NC \\
\hline Diastolic & $69.2(5.9)$ & $75.6(9.7)$ & $67.6(7.5)$ & $77.9(8.6)$ & NC \\
\hline \multicolumn{6}{|c|}{ Ambulatory blood pressure $(\mathrm{mm} \mathrm{Hg})$} \\
\hline \multicolumn{6}{|l|}{ Daytime } \\
\hline Systolic & $127.6(4.9)$ & $131.1(3.5)$ & $138.9(5.2)^{* * *, * *}$ & $143.4(4.6)^{* * * * * * *}$ & NC \\
\hline Diastolic & $74.8(4.5)$ & $78.6(3.8)$ & $84.2(7.9)^{* * *}$ & $85.3(4.9)^{* * *, * *}$ & NC \\
\hline Mean arterial pressure & $92.4(3.8)$ & $96.1(3.0)$ & $102.5(6.2)^{* * *, * *}$ & $104.6(4.3)^{* * * * * * *}$ & $<0.001$ \\
\hline Pulse pressure & $52.7(5.7)$ & $52.5(4.4)$ & $54.7(7.5)$ & $58.1(4.6)^{*}$ & $<0.01$ \\
\hline \multicolumn{6}{|l|}{$24 \mathrm{~h}$} \\
\hline Systolic & $125.6(4.2)$ & $131.1(5.9)^{*}$ & $136.2(5.0)^{* * *}$ & $141.7(4.2)^{* * * * * * *}$ & $<0.001$ \\
\hline Diastolic & $72.6(4.7)$ & $77.1(5.4)$ & $80.8(7.0)^{*}$ & $82.4(4.8)^{* * *}$ & $<0.001$ \\
\hline Mean arterial pressure & $89.9(3.9)$ & $94.8(4.9)^{*}$ & $98.9(5.3)^{* * *}$ & $101.8(4.1)^{* * *, * *}$ & $<0.001$ \\
\hline Pulse pressure & $53.0(5.0)$ & $54.0(5.6)$ & $55.4(7.5)$ & $59.3(4.4) \S$ & $<0.01$ \\
\hline \multicolumn{6}{|l|}{ Night-time } \\
\hline Systolic & $119.2(7.6)$ & $128.6(12.2)^{*}$ & $129.9(5.7)^{*}$ & $136.3(6.2)^{* * *}$ & $<0.001$ \\
\hline Diastolic & $64.9(6.3)$ & $71.5(10.2)$ & $71.1(10.7)$ & $73.2(6.3)^{*}$ & $<0.01$ \\
\hline Mean arterial pressure & $83.0(6.2)$ & $90.5(10.2)$ & $90.7(7.7)$ & $94.2(5.5)^{*}$ & $<0.001$ \\
\hline Pulse pressure & $54.3(5.4)$ & $57.1(8.6)$ & $58.8(11.4)$ & $63.0(6.2)^{*}$ & $<0.01$ \\
\hline
\end{tabular}

Values are shown as the mean (SD) or $\mathrm{n}(\%)$. Differences in means between all blood pressure subgroups were calculated using the analysis of variance test for trend for continuous variables and the linear-by-linear analysis for categorical variables. Differences in means between the subgroups were calculated using the Bonferroni procedure to control the risk of a type I error. $p$ is related to a linear-by-linear analysis for categorical variables. NC indicates not computed, because office and daytime ambulatory systolic and diastolic blood pressure values were used to categorise the participants.

${ }^{*} \mathrm{p}<0.05$ versus normotension (NT).

${ }^{* *} \mathrm{p}<0.05$ versus white coat hypertension (WCH).

$* * * \mathrm{p}<0.001$ versus NT.

$* * * * p<0.001$ versus WCH 
procedure to control the risk of a type I error (table 1). Included cases and controls were compared with the remaining players with high and optimal OBP, respectively, to test for selection bias.

Data are presented as mean $\pm \mathrm{SD}$ or as numbers (percentages). A $p<0.05$ was considered statistically significant, and all tests were two-tailed. The statistical analyses were conducted using SPSS (V.18.0; SPSS Inc).

\section{RESULTS}

\section{Individuals}

Of the 594 male professional football players, $250(42 \%)$ had optimal, 197 (33\%) normal, 108 (18\%) high normal, 37 (6\%) hypertension grade I and two had hypertension grade II. ${ }^{8}$ Twenty-six of the 28 (93\%) non-treated hypertensive players (cases) still living in Norway, and 26 controls were included in this study (figure 1). Table 2 shows the baseline characteristics of the study group. Compared with controls, cases had a significantly higher BMI, MAP and PP (table 2).

There were no differences between our controls $(n=26)$ and the remaining and not included football players with optimal BP $(n=224)$ regarding baseline characteristics, except the following: Our controls had higher DBP $(68.3 \pm 6.2$ vs $65.5 \pm 6.4 \mathrm{~mm} \mathrm{Hg}$; $\mathrm{p}<0.05)$ and MAP $(83.5 \pm 4.7$ vs $81.2 \pm 5.2 \mathrm{~mm} \mathrm{Hg} ; \mathrm{p}<0.05)$ than the not included controls $(n=224)$. There were also less black players ( 1 vs $4 ; \mathrm{p}<0.05)$ among the cases than among the not included cases $(n=11)$.

\section{Ambulatory blood pressure}

Table 3 shows the ABP results separately for cases and controls. Overall, the players' mean age was 28.3 years (range 20-35). Significant correlation was found between office and ambulatory daytime MAP $\left(\mathrm{R}^{2}=0.21 ; \mathrm{p}<0.01\right)$. Compared with controls, cases had significantly higher daytime SBP, DBP and MAP, which was also the case for $24 \mathrm{~h}$ and night-time ABP (table 3). Mean night-time ABP was high in $23(88 \%)$ of the cases, and in $16(64 \%)$ of the controls. The cases had less nocturnal BP fall for both SBP and DBP, but the differences were not significant. Nine (35\%) cases and $11(42 \%)$ controls had less than $10 \%$ nocturnal dip in BP.

Table 1 shows the prevalence of all players divided into four BP subgroups: Among the 26 controls, 17 (65\%) had true normotension, while 9 (35\%) had masked hypertension. Among the 26 cases, $15(58 \%)$ had sustained hypertension, while $11(42 \%)$ had white coat hypertension. Figure 2 illustrates a

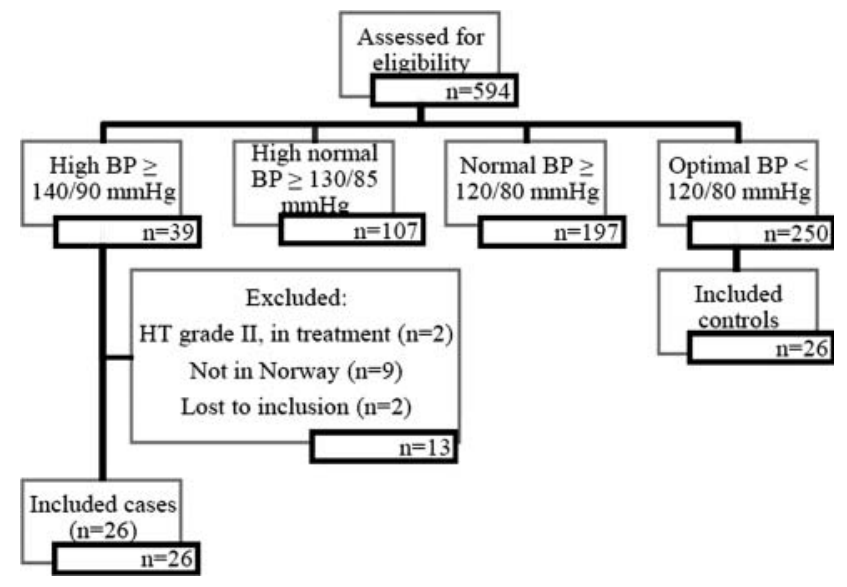

Figure 1 Study flow chart. HT, hypertension.
Table 2 Baseline characteristics of the study group in 2008

\begin{tabular}{|c|c|c|c|}
\hline Characteristics & Controls $(n=26)$ & Cases $(n=26)$ & p Value \\
\hline Age (years) & $25.2(4.2)$ & $25.9(3.9)$ & 0.71 \\
\hline Male gender, $\mathrm{n}(\%)$ & $26(100)$ & $26(100)$ & \\
\hline BMI $\left(\mathrm{kg} / \mathrm{m}^{2}\right)$ & $23.2(0.9)$ & $23.7(1.1)$ & $<0.05$ \\
\hline Heart rate (beats/min) & $64.3(8.1)$ & $61.6(7.4)$ & 0.22 \\
\hline \multicolumn{4}{|c|}{ Office blood pressure $(\mathrm{mm} \mathrm{Hg})$} \\
\hline Systolic & $114.2(3.8)$ & $144.1(7.5)$ & NC \\
\hline Diastolic & $68.7(6.4)$ & $76.9(9.0)$ & NC \\
\hline Mean arterial pressure & $83.9(5.0)$ & $99.3(6.3)$ & $<0.001$ \\
\hline Pulse pressure & $45.6(5.6)$ & $67.2(12.0)$ & $<0.001$ \\
\hline \multicolumn{4}{|l|}{ Race or ethnic group (n) } \\
\hline White & 23 & 23 & \\
\hline Black & 1 & 1 & \\
\hline Others & 2 & 2 & \\
\hline \multicolumn{4}{|l|}{ Age group (years) } \\
\hline $20-23$ & 4 & 5 & \\
\hline $24-27$ & 8 & 7 & \\
\hline $28-31$ & 9 & 9 & \\
\hline $32-35$ & 5 & 5 & \\
\hline \multicolumn{4}{|c|}{$\begin{array}{l}\text { Values are shown as the mean (SD) or } n(\%) . p \text { is related to the } t \text { test for continuous } \\
\text { versus categorical variables, and to Fisher's exact test for categorical variables. NC } \\
\text { indicates not computed, because office systolic and diastolic blood pressure values } \\
\text { were used to categorise the participants. } \\
\text { BMI, body mass index. }\end{array}$} \\
\hline
\end{tabular}

significant linear relationship between BP subgroups for daytime ambulatory SBP and DBP. Table 1 shows the same characteristics for $24 \mathrm{~h}$ and night-time ABP, including MAP and PP. The relationship was not significant for HR.

In all, $24(46 \%)$ players had high daytime ABP (table 1). If high ABP instead was defined according to cut-off values for 24 h or night-time ABP, 34 (65\%) or 39 (75\%), respectively, had high ABP. Nine (38\%) of the players had isolated ambulatory systolic daytime hypertension. The players did not report the use of any medication or extraordinary events during the 24-h $\mathrm{ABP}$ recordings that should affect the results.

\section{Follow-up of BP recordings}

After the screening in 2008, 16 (62\%) cases and 16 (62\%) controls had new OBP recordings as part of the football teams' annual screening. One case was at the family physician and had an ABP recording. Two players with hypertension grade II had received antihypertensive treatment and were not included in this study.

\section{DISCUSSION}

The main and novel findings of the present study were a high prevalence of masked hypertension (35\%), high ABP during night-time and a random follow-up of high OBP after preparticipation screening of male professional football players. We consider high ABP, both day and night, to be of particular interest, since all participants were young athletes.

\section{Masked hypertension in young athletes}

If we extrapolate the results from this case-control study to the entire cohort of 555 professional football players without high OBP in the preparticipation screening study, the number of players with masked hypertension would have been 192 (35\%), or $32 \%$ of all players $(n=594)$, which seems to be higher than expected. There are, however, no studies of ABP in young athletes and limited knowledge of ABP in healthy young men. The 
Table 3 Ambulatory blood pressure of the study group in 2010

\begin{tabular}{|c|c|c|c|}
\hline Characteristics & Controls $(n=26)$ & Cases $(n=26)$ & $p$ Value \\
\hline Age (years) & $28.0(4.3)$ & $28.5(3.8)$ & 0.71 \\
\hline Heart rate (beats/min) & $63.6(6.7)$ & $62.4(8.7)$ & 0.57 \\
\hline \multicolumn{4}{|c|}{ Ambulatory blood pressure $(\mathrm{mm} \mathrm{Hg})$} \\
\hline \multicolumn{4}{|l|}{ Daytime } \\
\hline Systolic & $131.5(7.4)$ & $138.2(7.4)$ & $<0.01$ \\
\hline Diastolic & $78.1(7.3)$ & $82.4(5.5)$ & $<0.01$ \\
\hline Mean arterial pressure & $95.9(6.7)$ & $101.0(5.7)$ & $<0.01$ \\
\hline Pulse pressure & $53.4(6.3)$ & $55.7(5.3)$ & 0.09 \\
\hline \multicolumn{4}{|l|}{$24 \mathrm{~h}$} \\
\hline Systolic & $129.3(6.8)$ & $137.2(7.2)$ & $<0.001$ \\
\hline Diastolic & $75.4(6.7)$ & $80.2(5.6)$ & $<0.01$ \\
\hline Mean arterial pressure & $93.4(6.2)$ & $99.2(5.6)$ & $<0.001$ \\
\hline Pulse pressure & $53.8(5.9)$ & $57.0(5.5)$ & $<0.05$ \\
\hline \multicolumn{4}{|l|}{ Night-time } \\
\hline Systolic & $123.0(8.6)$ & $133.1(10.0)$ & $<0.001$ \\
\hline Diastolic & $67.1(8.5)$ & $73.0(7.9)$ & $<0.01$ \\
\hline Mean arterial pressure & $85.8(7.6)$ & $93.0(7.9)$ & $<0.01$ \\
\hline Pulse pressure & $55.9(8.2)$ & $60.1(7.6)$ & $<0.05$ \\
\hline \multicolumn{4}{|l|}{$\Delta$ Day-night } \\
\hline Systolic & $8.7(7.5)$ & $4.7(8.2)$ & 0.09 \\
\hline Diastolic & $10.9(7.0)$ & $9.5(6.4)$ & 0.35 \\
\hline
\end{tabular}

most comparable results derive from Schettini et al's ${ }^{6}$ general population study, showing similar office and ambulatory SBP in 20 -year-old to 39-year-old men, and from Selenta $e$ t $a l^{15}$ reporting masked hypertension prevalence of $23 \%$ among 319 normotensive participants $(50 \%$ men) with a mean age of 27 years (range 17-68 years). In Verberk et al's ${ }^{16}$ meta-analysis based on 24 studies of both genders from 20 to 72 years, the prevalence of masked hypertension was $19 \pm 4 \%$, varying from $1 \%$ to $61 \%$. In Bobrie et al's ${ }^{17}$ systematic review, the prevalence varied from $8 \%$ to $48 \%$. Both studies included papers with major distinctions in measurement methods, cut-off values, age, sex and participating patients; normotensives, untreated or treated hypertensive patients.

Considering that Schettini et al and Selenta et al are showing approximately the correct prevalence of masked hypertension in young men, it is essential to identify whether our results reflect a true higher prevalence of masked hypertension in young male athletes. In this context, it is important to emphasise that the prevalence of masked hypertension in a study population will be relatively higher when only patients with normotension are included, or when the prevalence of hypertension is low, as in our study. The opposite holds good when all BP categories are included or when the prevalence of hypertension is high. Moreover, the inclusion rate of $93 \%$ of possible cases in the present study and no clinically important selection bias among the controls may support that our results are representative of young male professional football players.

On the other hand, our results might reflect an overestimation of masked hypertension due to 'spurious systolic hypertension', which might be an innocent clinical condition of isolated systolic hypertension in physically active people. ${ }^{18}$ Athletes may have increased PP and SBP, while DBP is normal according to a higher resting stroke volume and cardiac output, resulting in the central systolic pressure being normal and much lower than the
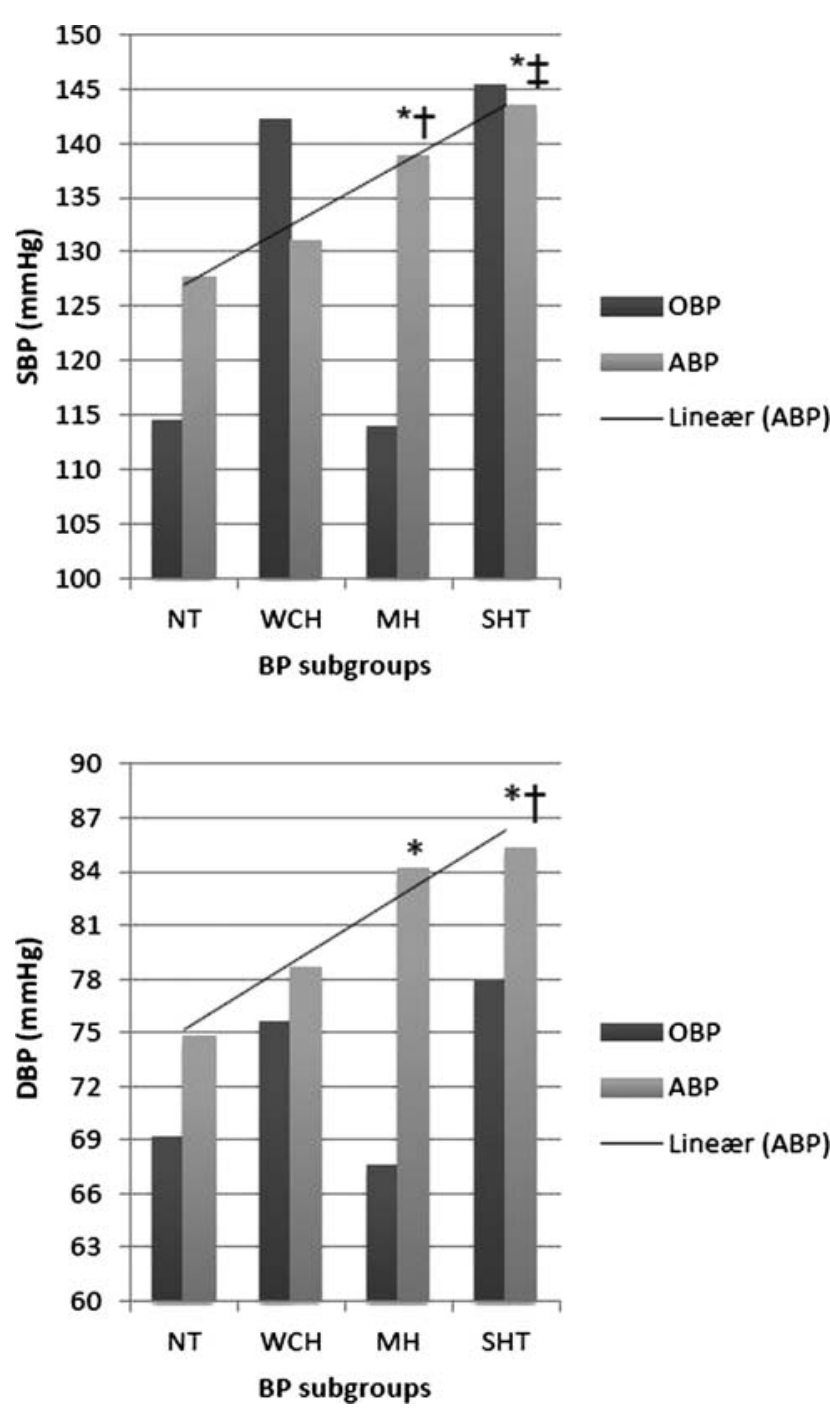

Figure 2 Office blood pressure (OBP) and daytime ambulatory blood pressure $(A B P)$ of the study group. The diagram illustrates the significant linear relationship for BP subgroups (normotension (NT), white coat hypertension (WCH), masked hypertension (MH) and sustained hypertension $(S H T)$ ) versus mean $( \pm S D)$ daytime ambulatory systolic and diastolic $\mathrm{BP}$, and the differences between BP subgroups. ${ }^{*} p<0.001$ versus NT, $\uparrow p<0.05$ versus $W C H, \neq p<0.001$ versus $W C H$.

brachial systolic pressure. ${ }^{18}$ However, only 38\% of the hypertensive players in our study had isolated ambulatory systolic hypertension. Our small number of participants and thus less statistical power have also to be taken into consideration. Hence, two players with more or less high ABP would have changed the prevalence of masked hypertension to $42 \%$ and $27 \%$ (40\% and $25 \%$ of all players), respectively. The lower estimated value $(27 \%)$ will still be of considerable size and clinical importance.

\section{Masked hypertension and increased sympathetic activity}

There was a significant positive linear relationship between the increasing PP and ABP subgroups, indicating increased sympathetic activity, which has been considered as one of the underlying physiological mechanisms of masked hypertension, similar to sustained hypertension. ${ }^{19}$ Players with high OBP had less nocturnal BP fall than players with optimal BP, which may indicate increased sympathetic activity in these players. This might 
be due to mental stress because of a high number of matches during the season and hence the lack of sufficient recovery. The significant association, however, between BP and resting HR reported in our previous study ${ }^{8}$ was not repeated for ambulatory $\mathrm{HR}$, which is in accordance with other studies of variance of HR, related to OBP and ABP. ${ }^{20}$ Fagard et al ${ }^{20}$ suggest that the 'white-coat' effect with stimulation of the sympathetic nervous system when BP is measured by an investigator can explain the stronger relationships between HR and OBP than between HR and ABP.

\section{Clinical implications}

Although the diagnoses of masked hypertension without repeated OBP recordings do not strictly follow the ESH's guidelines, ${ }^{3}$ players with high ABP should be regarded as hypertensive because of the superiority of ABP compared with OBP in predicting CV events. ${ }^{4}$ Verdecchia et $a l^{21}$ have suggested that prognosis is worse when the BP load is persistent throughout the $24 \mathrm{~h}$ than when limited to the daytime hours and that hypertension in young adults increases the CV risk, because of the persistent BP load over many years. Although the risk for CV morbidity and mortality is comparable for subjects with masked and sustained hypertension in meta-analysis, ${ }^{13}$ this is not validated in a young study population. Isolated systolic hypertension could also decrease the $\mathrm{CV}$ risk according to a small recent study of young subjects with isolated systolic hypertension and low central BP. ${ }^{22}$ Besides, young healthy athletes, slim and physically active, commonly score better than the general population of similar age regarding $\mathrm{CV}$ risk factors. ${ }^{21}$

Only $65 \%$ of the players with high OBP in the preparticipation screening study had additional BP recordings, which reflect poor compliance with the guidelines in this area. ${ }^{3}$ The reason for this inconsistency might be that the positive findings of high BT in otherwise healthy young athletes were not sufficiently emphasised. The challenge, however, is to select for follow-up only the players with increased risk, especially when the OBP is normal.

\section{Limitations}

OBP and ABP were not recorded simultaneously and not repeated. Different BP devices were used for OBP and ABP without any agreement analyses; however, there was significant correlation between office and ambulatory daytime MAP.

The ABP recordings were conducted over a limited time period, yet with a different number of workouts for each player. However, owing to the individual matching of case and control within football teams, weekly exercise was still comparable within pairs.

We used no questionnaires regarding personality, earlier diagnoses of high OBP or level of anxiety or stress. Persons with higher levels of type A personality usually have higher $\mathrm{OBP}^{23}$ and earlier hypertension labelling has been proven in other studies to increase OBP. ${ }^{5}{ }^{24}$ Increased physical activity and psychosocial factors such as anxiety and job stress may selectively raise the $\mathrm{ABP}$ relative to $\mathrm{OBP}^{13}$

The prevalence of high OBP could have been underestimated in the preparticipation screening study due to postexercise hypotension, ${ }^{25}$ since some of the players, owing to strict timetables, had been exercising up to $1 \mathrm{~h}$ before the BP recordings. ${ }^{8}$ This was, however, not representative of the majority of the players. We therefore consider that this cannot explain the present high prevalence of players with masked hypertension.

\section{Perspective}

In conclusion, this is the first study of $\mathrm{ABP}$ in young athletes to reveal a high prevalence of masked hypertension in male professional football players. One reason for this might be enhanced sympathetic activity, which is indicated by high ABP during night-time, lack of nocturnal dip in BP and a significant linear relationship between increasing BP subgroups and PP. Repeated measures of high BP appear random, and we recommend a closer focus on follow-up of BP screening results in athletes.

\section{What are the new findings?}

- This is the first study of ambulatory blood pressure in young athletes.

- There is a high prevalence of masked hypertension (normal office blood pressure and high ambulatory blood pressure) in professional male football players. This is an independent risk factor for cardiovascular disease.

- Ambulatory blood pressure during night-time is also high in more than half of the players.

- The players' follow-up of high office blood pressure from preparticipation screening is often random.

\section{How might it impact on clinical practice in the near}

\section{future?}

- We will get a closer focus on blood pressure measurements during preparticipation screening.

- Ambulatory blood pressure monitoring will be performed when appropriate.

Follow-up of high blood pressure will be organised.

Acknowledgements The Oslo Sports Trauma Research Center has been established at the Norwegian School of Sport Sciences through generous grants from the Royal Norwegian Ministry of Culture, the South-Eastern Norway Regional Health Authority, the International Olympic Committee, the Norwegian Olympic Committee \& Confederation of Sport, and Norsk Tipping AS. The authors would like to thank all the players who participated in the study and Professor Ingar M K Holme for statistical support.

Contributors HMB designed the study, collected all the data, wrote the statistical analysis plan, cleaned and analysed the data, and drafted and revised the paper. She is the guarantor. EES designed the preparticipation study and monitored data collection for the trial, contributed to the design of this study and revised the paper. TEA designed the preparticipation study and monitored data collection for the trial, contributed to the design of this study, and revised the paper. KS designed the preparticipation study and monitored data collection for the trial, contributed to the design of this study, monitored data collection for this study, analysed the data and drafted and revised the paper.

Funding This research was supported by the Oslo Sports Trauma Research Center, Oslo, Norway, and the Akershus University Hospital, Lørenskog, Norway.

\section{Competing interests None.}

Ethics approval The Regional Committee for Medical Research Ethics, South-Eastern Norway Regional Health Authority, Norway.

Provenance and peer review Not commissioned; internally peer reviewed.

\section{REFERENCES}

1 Sealy DP, Pekarek L, Russ D, et al. Vital signs and demographics in the preparticipation sports exam: do they help us find the elusive athlete at risk for sudden cardiac death? Curr Sports Med Rep 2010;9:338-41.

2 Reims $H$, Fossum E, Kjeldsen SE, et al. Home blood pressure monitoring. Current knowledge and directions for future research. Blood Press 2001;10:271-87. 
3 Mancia G, De BG, Dominiczak A, et al. 2007 Guidelines for the Management of Arterial Hypertension: the task force for the management of arterial hypertension of the European Society of Hypertension (ESH) and of the European Society of Cardiology (ESC). J Hypertens 2007;25:1105-87.

4 Pickering TG, Davidson K, Gerin W, et al. Masked hypertension. Hypertension 2002;40:795-6.

5 Pickering TG, Gerin W, Schwartz JE, et al. Franz Volhard lecture: should doctors still measure blood pressure? The missing patients with masked hypertension. $J$ Hypertens 2008;26:2259-67.

6 Schettini C, Bianchi M, Nieto F, et al. Ambulatory blood pressure: normality and comparison with other measurements. Hypertension Working Group. Hypertension 1999;34:818-25.

7 Verberk WJ, Thien T, De Leeuw PW. Masked hypertension, a review of the literature. Blood Press Monit 2007;12:267-73.

8 Berge $\mathrm{H}, \mathrm{Gjerdalen} \mathrm{G}$, Andersen TE, et al. Blood pressure in professional male football players in Norway. J Hyperten 2013;31:672-9. doi:10.1097/HJH. Ob013e32835eb5fe

9 Dart AM, Kingwell BA. Pulse pressure-a review of mechanisms and clinical relevance. J Am Coll Cardiol 2001;37:975-84.

10 Tjugen TB, Flaa A, Kjeldsen SE. The prognostic significance of heart rate for cardiovascular disease and hypertension. Curr Hypertens Rep 2010;12:162-9.

11 UEFA Medical Committee. UEFA club licensing system clarification memo No. 11 1-8. 30-11-2006. Ref Type: Generic

12 Pickering TG, White WB, Giles TD, et al. When and how to use self (home) and ambulatory blood pressure monitoring. J Am Soc Hypertens 2010;4:56-61.

13 Ogedegbe G, Agyemang C, Ravenell JE. Masked hypertension: evidence of the need to treat. Curr Hypertens Rep 2010;12:349-55.

14 Sherwood A, Steffen PR, Blumenthal JA, et al. Nighttime blood pressure dipping: the role of the sympathetic nervous system. Am J Hypertens 2002;15:111-18.
15 Selenta $\mathrm{C}$, Hogan BE, Linden W. How often do office blood pressure measurements fail to identify true hypertension? An exploration of white-coat normotension. Arch Fam Med 2000;9:533-40.

16 Verberk WJ, Kessels AG, De Leeuw PW. Prevalence, causes, and consequences of masked hypertension: a meta-analysis. Am J Hypertens 2008:21:969-75.

17 Bobrie G, Clerson P, Menard J, et al. Masked hypertension: a systematic review. $J$ Hypertens 2008;26:1715-25.

18 Palatini P. Cardiovascular effects of exercise in young hypertensives. Int J Sports Med 2012;33:683-90.

19 Grassi G. Assessment of sympathetic cardiovascular drive in human hypertension: achievements and perspectives. Hypertension 2009;54:690-7.

20 Fagard $\mathrm{RH}$, Pardaens K, Staessen JA. Relationships of heart rate and heart rate variability with conventional and ambulatory blood pressure in the population. J Hypertens 2001:19:389-97.

21 Verdecchia P. Prognostic value of ambulatory blood pressure: current evidence and clinical implications. Hypertension 2000;35:844-51.

22 Saladini F, Santonastaso M, Mos L, et al. Isolated systolic hypertension of young-to-middle-age individuals implies a relatively low risk of developing hypertension needing treatment when central blood pressure is low. J Hypertens 2011;29:1311-19.

23 Konstantopoulou AS, Konstantopoulou PS, Papargyriou IK, et al. Masked, white coat and sustained hypertension: comparison of target organ damage and psychometric parameters. J Hum Hypertens 2010;24:151-7.

24 Rostrup M, Kjeldsen SE, Eide IK. Awareness of hypertension increases blood pressure and sympathetic responses to cold pressor test. Am J Hypertens 1990;3:912-17.

25 Pescatello LS, Franklin BA, Fagard R, et al. American College of Sports Medicine position stand. Exercise and hypertension. Med Sci Sports Exerc 2004:36:533-53. 